\title{
Dark-Binding Process Relevant to Preventing Photosensitized \\ Oxidation: Conformation Dependent Light and Dark Mechanisms \\ by a Dual-Functioning Diketone
}

Sarah J. Belh ${ }^{\dagger, \star}$, Niluksha Walalawela $a^{\dagger, \star}$, Stas Lekhtman ${ }^{\dagger}$, and Alexander Greer ${ }^{\dagger, \hbar * *}$

†Department of Chemistry, Brooklyn College, 2900 Bedford Avenue, Brooklyn, New York 11210, United States

${ }^{\star}$ Ph.D. Program in Chemistry, The Graduate Center of the City University of New York, 365 Fifth Avenue, New York, New York 10016, United States

\section{Supporting Information}

Table of Contents

Figure S1. Schematic of the photoreactor setup.

Figure $\mathrm{S} 2 .{ }^{1} \mathrm{H}$ NMR spectra of $(\mathrm{MeO})_{3} \mathrm{P}$ and phosphorane $\mathbf{4}$ in $\mathrm{CD}_{3} \mathrm{CN}$. $\mathrm{S} 3$

Figure S3. ${ }^{1} \mathrm{H}$ NMR spectra of 4,4'-dimethylbenzil 1 and phosphorane 4 in $\mathrm{CD}_{3} \mathrm{CN} . \quad \mathrm{S} 4$

Figure S4. ${ }^{31} \mathrm{P}$ NMR spectra of $(\mathrm{MeO})_{3} \mathrm{P},(\mathrm{MeO})_{3} \mathrm{P}=\mathrm{O}$, and phosphorane 4 in $\mathrm{CD}_{3} \mathrm{CN} . \quad$ S5

Figure S5. Absorption spectra of reagents, products, and filter solution in $\mathrm{CH}_{3} \mathrm{CN} . \quad$ S6

Figure S6. Absorption and fluorescence spectra of 4,4'-dimethylbenzil $\mathbf{1}$ in $\mathrm{CH}_{3} \mathrm{CN} . \quad$ S7

Figure S7. Absorption spectra of the reaction mixture of 1 with $(\mathrm{MeO})_{3} \mathrm{P}$ in $\mathrm{CH}_{3} \mathrm{CN} . \quad$ S8

$\begin{array}{ll}\text { Figure S8. Kinetic plot and R square fitting of the kinetic data. } & \text { S9 }\end{array}$ 


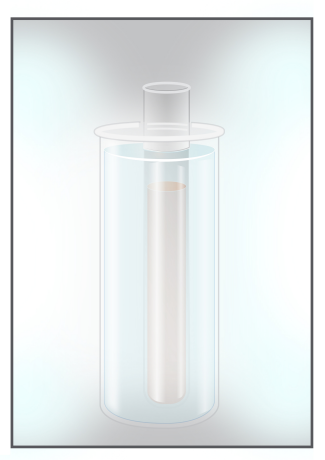

a

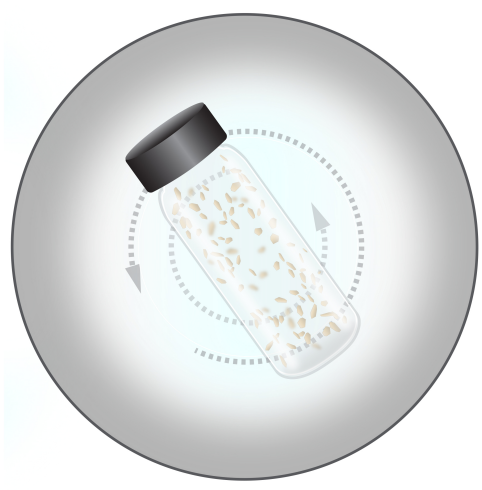

b

Figure S1. Schematic of the photoreactor set up. A metal-halide lamp system was used for the irradiation of homogeneous solution (a) or silica particles tumbling inside of a vial (b). Light was filtered through a potassium hydrogen phthalate filter solution $(300<\lambda<700 \mathrm{~nm})$ for the homogeneous studies and unfiltered $(280<\lambda<700 \mathrm{~nm})$ for the heterogeneous studies. 

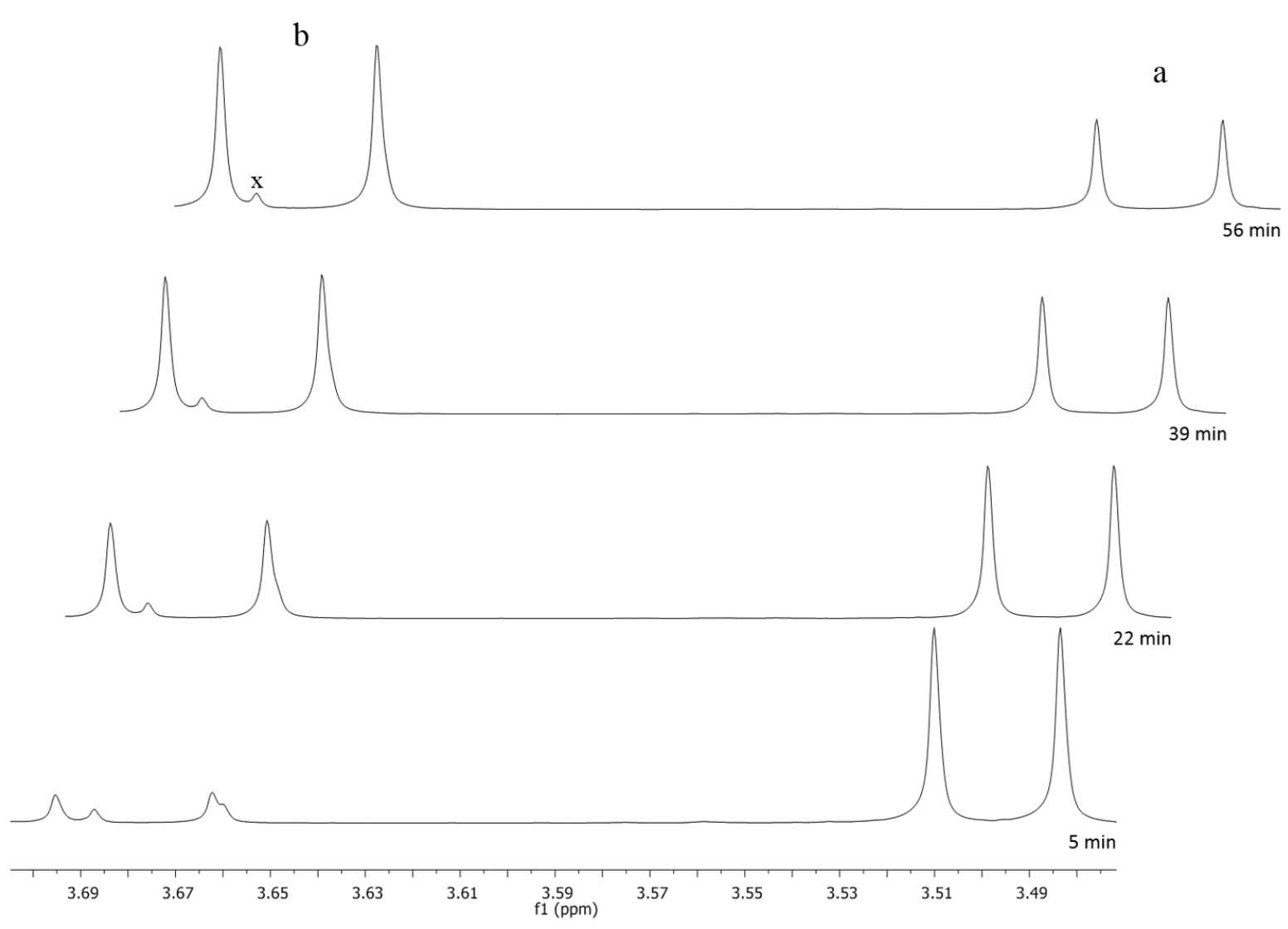

Figure S2. Partial ${ }^{1} \mathrm{H}$ NMR spectra following the photoreaction of 4,4'-dimethylbenzil 1, dicumyl peroxide 3, and $(\mathrm{MeO})_{3} \mathrm{P}$ in $\mathrm{CD}_{3} \mathrm{CN}$. Spectra were recorded after irradiation times of 5, 22, 39 and $56 \mathrm{~min}$. The $(\mathrm{MeO})_{3} \mathrm{P}$ peaks "a" at $3.48 \mathrm{ppm}$ and $3.51 \mathrm{ppm}(\mathrm{d}, J=10.6 \mathrm{~Hz}, 9 \mathrm{H})$ are found to recede with time, whereas the phosphorane 4 peaks "b" at $3.66 \mathrm{ppm}$ and $3.69 \mathrm{ppm}(\mathrm{d}, J=13.2 \mathrm{~Hz}, 9 \mathrm{H})$ increase with time. The peak marked " $x$ " is due to an impurity. 


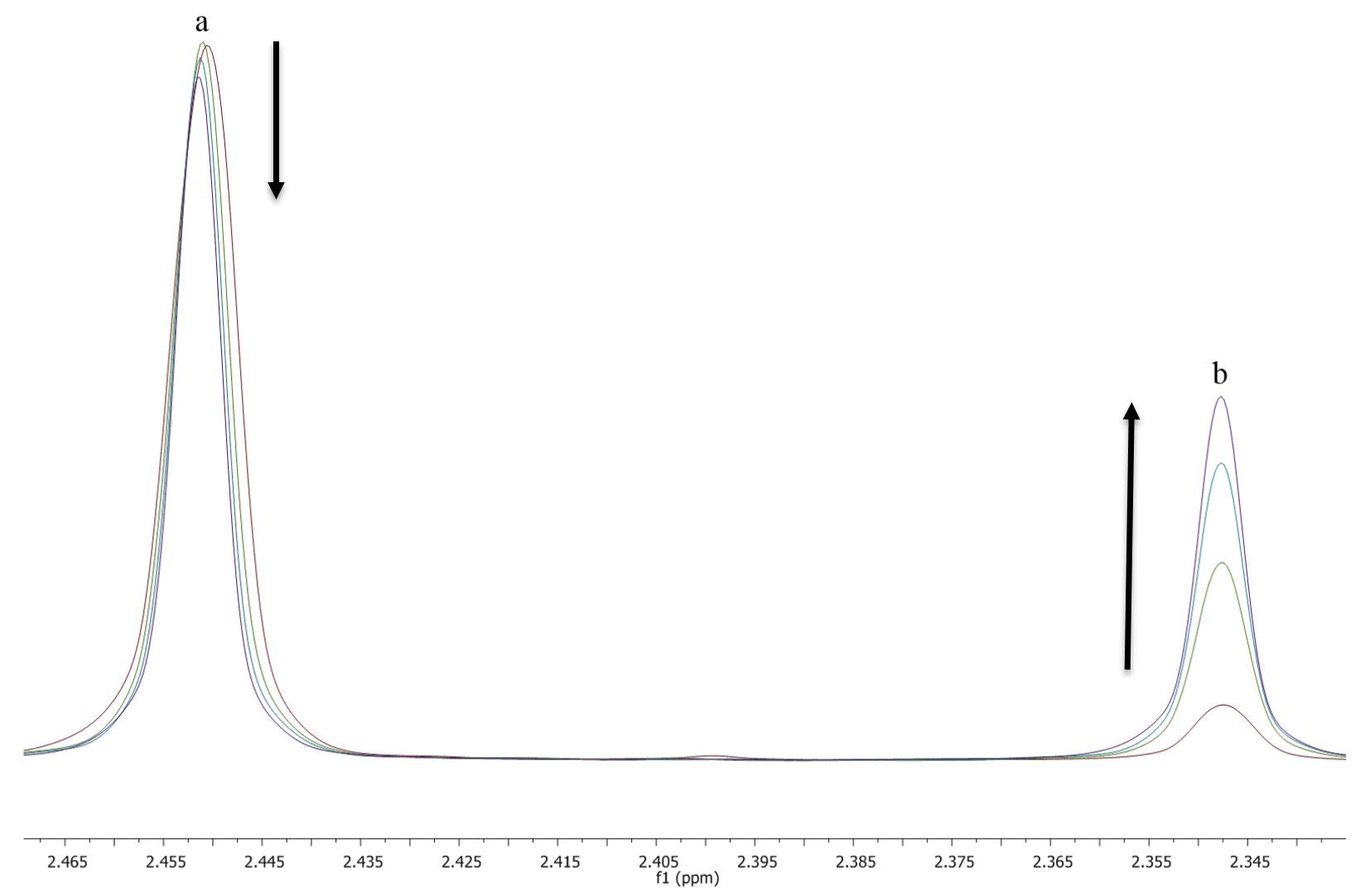

Figure S3. Partial ${ }^{1} \mathrm{H}$ NMR spectra following the dark reaction between 4,4'-dimethylbenzil 1 and $(\mathrm{MeO})_{3} \mathrm{P}$ in $\mathrm{CD}_{3} \mathrm{CN}$ at $5 \mathrm{~min}$ (red), $22 \mathrm{~min}$ (green), $39 \mathrm{~min}$ (blue) and $56 \mathrm{~min}$ (purple). The $p$ substituted methyls were assigned to the 4,4'-dimethylbenzil 1 peak "a" at 2.451 ppm and the phosphorane 4 peak " $b$ ” at 2.350 ppm. 

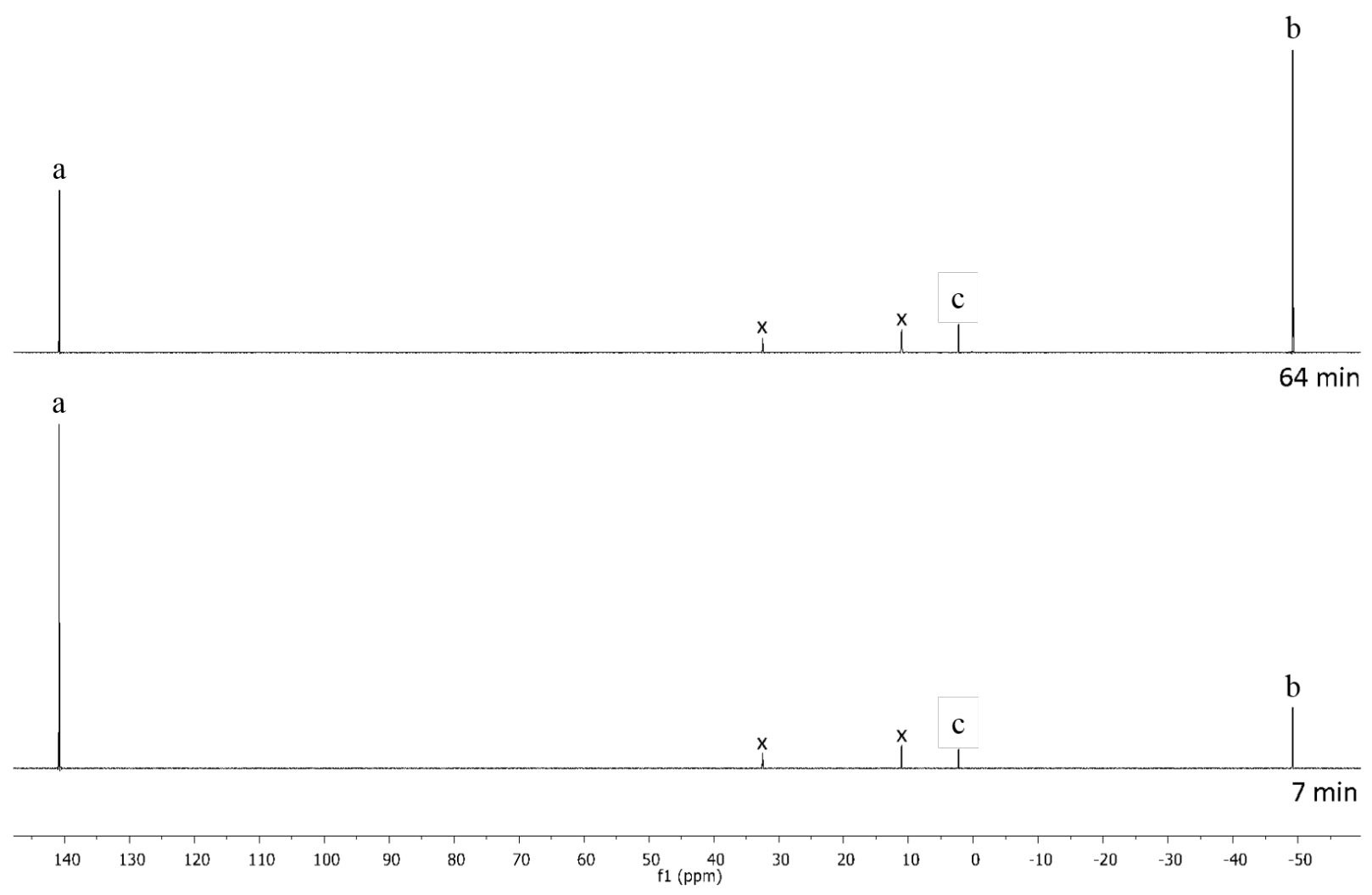

Figure S4. ${ }^{31} \mathrm{P}$ NMR spectra following the photoreaction of 4,4'-dimethylbenzil 1, dicumyl peroxide 3, and (MeO) $)_{3} \mathrm{P}$ in $\mathrm{CD}_{3} \mathrm{CN}$ compared to an $\mathrm{H}_{3} \mathrm{PO}_{4}$ standard. Spectra were recorded after irradiation times of 7 and $64 \mathrm{~min}$. The $(\mathrm{MeO})_{3} \mathrm{P}$ peak "a" at $140.8 \mathrm{ppm}$ is found to recede with time, whereas the phosphorane 4 peak " $\mathrm{b}$ " at $-49.6 \mathrm{ppm}$ and the $(\mathrm{MeO})_{3} \mathrm{P}=\mathrm{O}$ peak "c" at $2.25 \mathrm{ppm}$ increase with time. Peaks marked " $x$ " are due to impurities. 


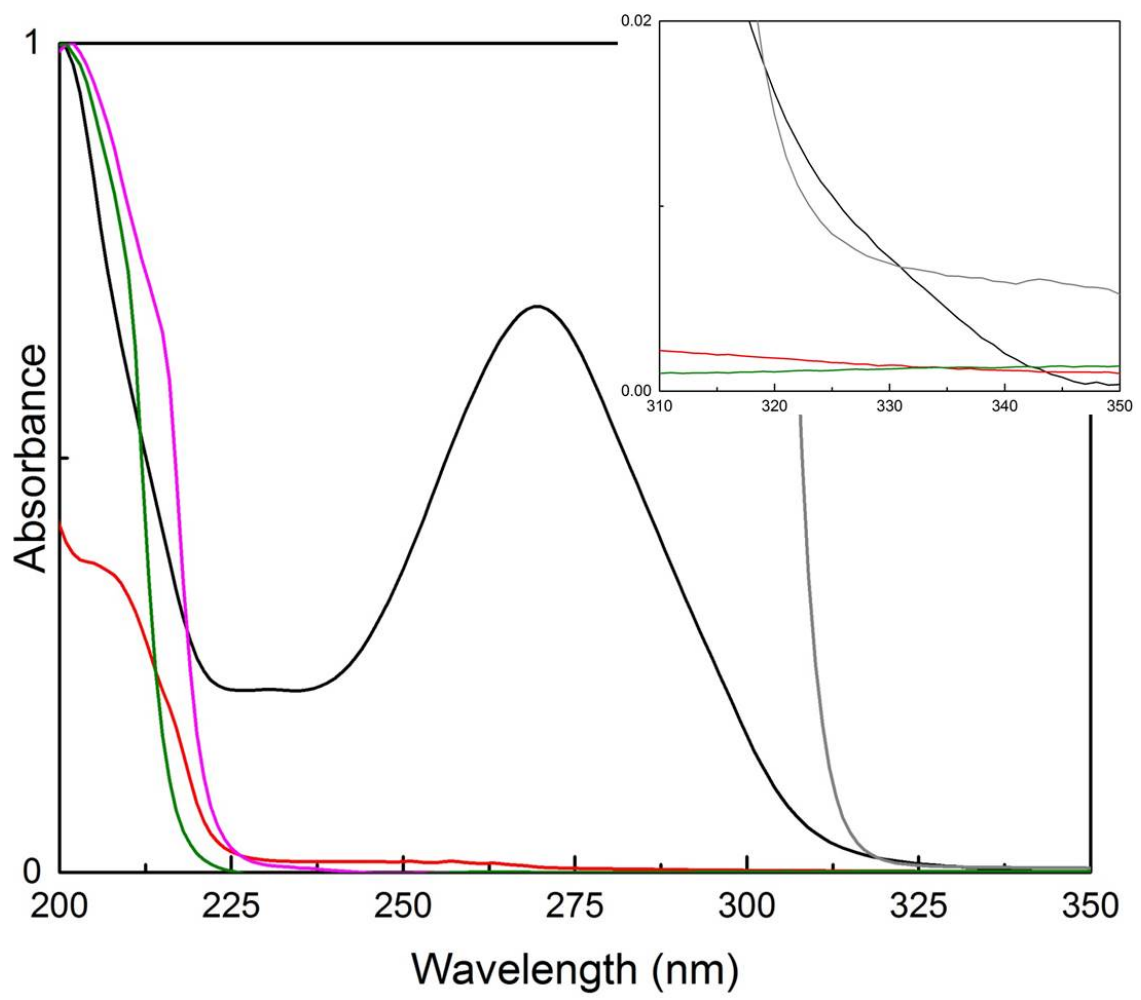

Figure S5. Absorption spectra of 4,4'-dimethylbenzil 1 (black trace), dicumyl peroxide 3 (red trace), $(\mathrm{MeO})_{3} \mathrm{P}$ (magenta trace), $(\mathrm{MeO})_{3} \mathrm{P}=\mathrm{O}$ (green trace), and the potassium phthalate filter solution (gray trace, it is a cutoff filter $310 \mathrm{~nm}$ ) in $\mathrm{CH}_{3} \mathrm{CN}$ (path length $=1.0 \mathrm{~cm}$ ). The inset shows the absorption of the compounds and filter solution in the 310 to $350 \mathrm{~nm}$ range. 


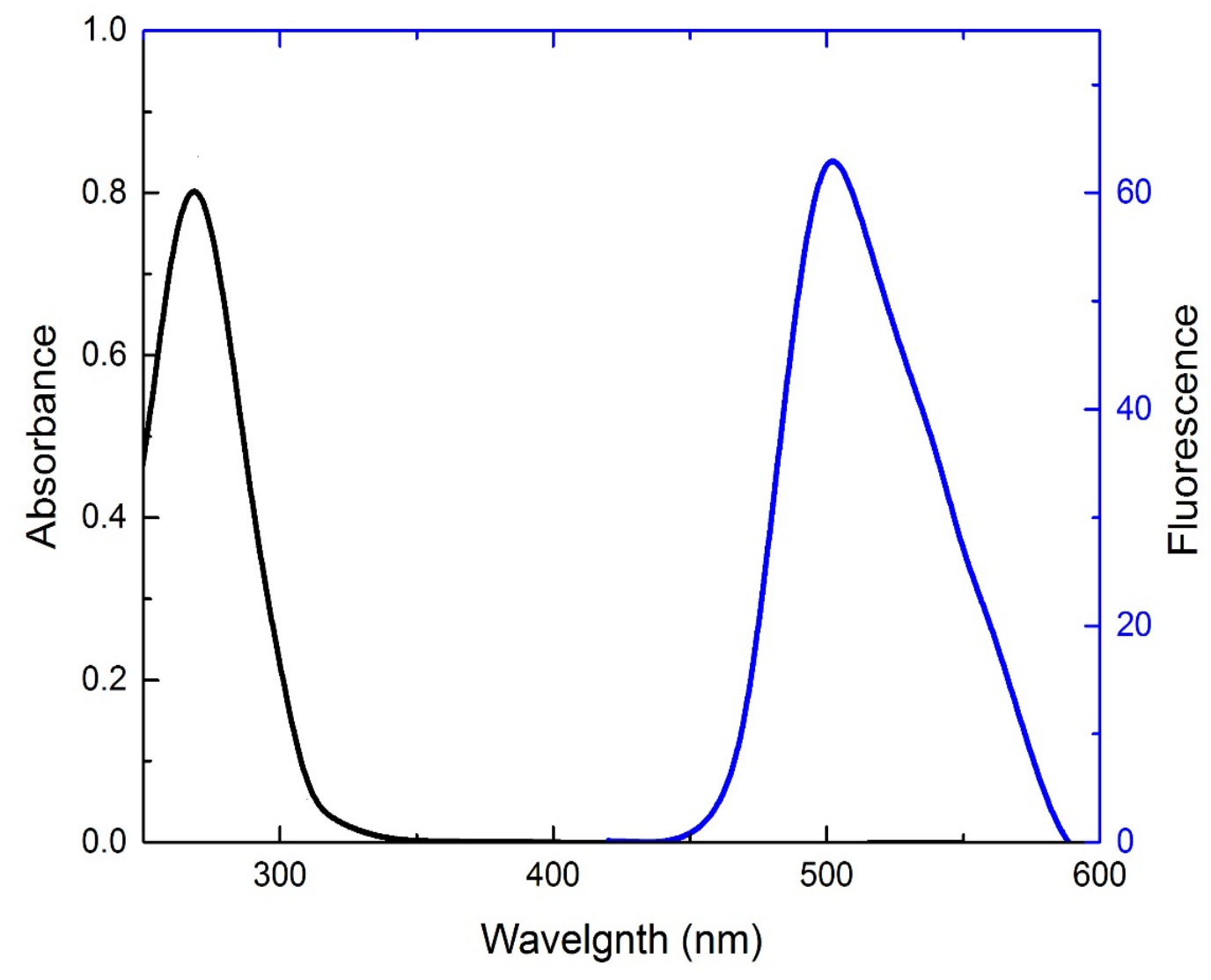

Figure S6. Absorption spectrum (black trace; $\lambda_{\max }=270 \mathrm{~nm}$ ) and fluorescence spectrum (blue trace; $\lambda_{\mathrm{ex}}=270 \mathrm{~nm}$ ) of $4,4^{\prime}$-dimethylbenzil 1 in $\mathrm{CH}_{3} \mathrm{CN}$. Path length $=1.0 \mathrm{~cm}$. 


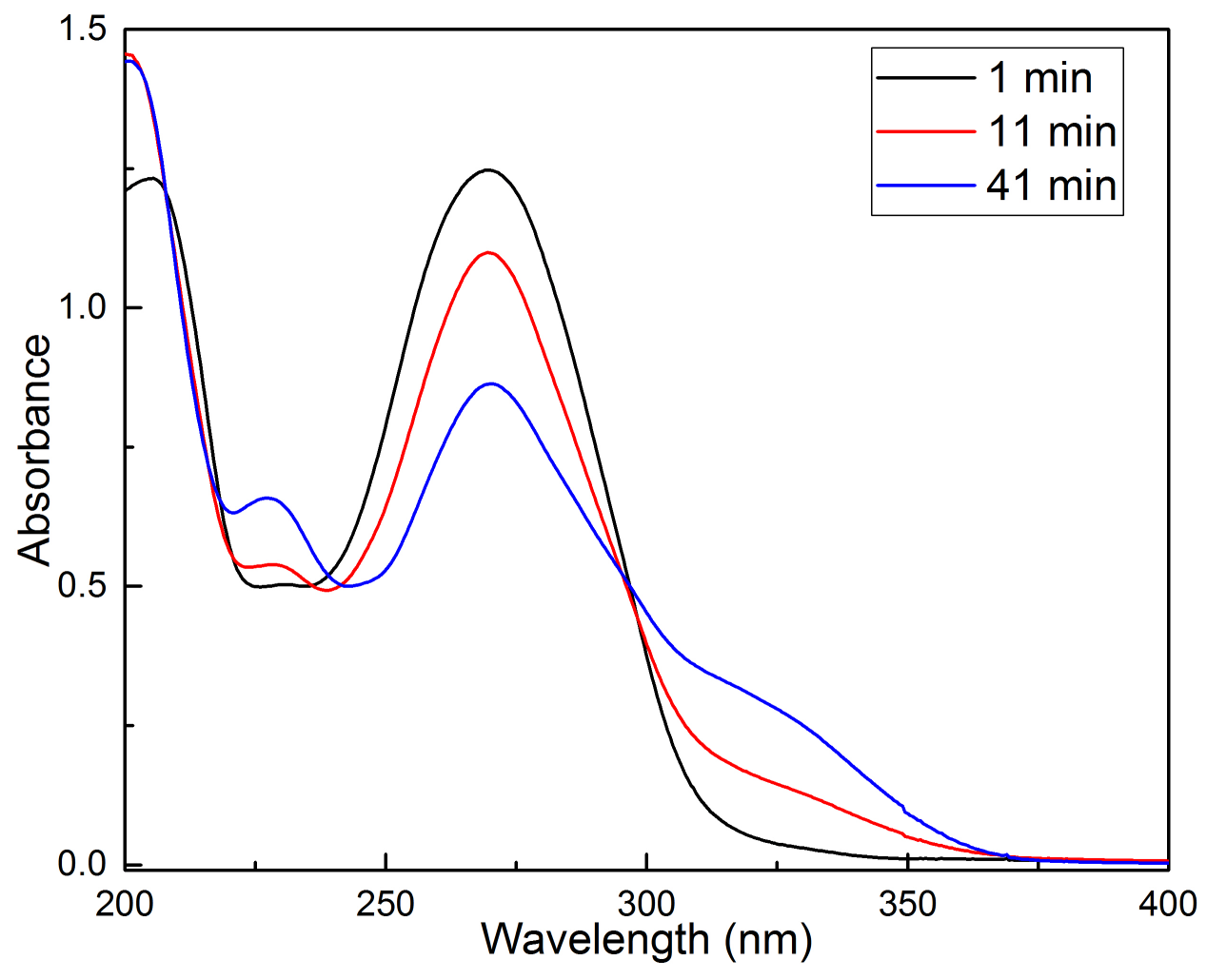

Figure S7. Absorption spectra following a dark reaction of 4,4'-dimethylbenzil $1\left(\lambda_{\max }=270 \mathrm{~nm}\right)$ and $(\mathrm{MeO})_{3} \mathrm{P}$, which forms phosphorane $4\left(\lambda_{\max }=235 \mathrm{~nm}\right)$ and by-products in $\mathrm{CH}_{3} \mathrm{CN}$. Spectra were recorded after 1, 11, and $41 \mathrm{~min}$. At $41 \mathrm{~min}$, the mixture contains 4,4'-dimethylbenzil 1 and phosphorane $\mathbf{4}$ in a ratio of about 1:1. 


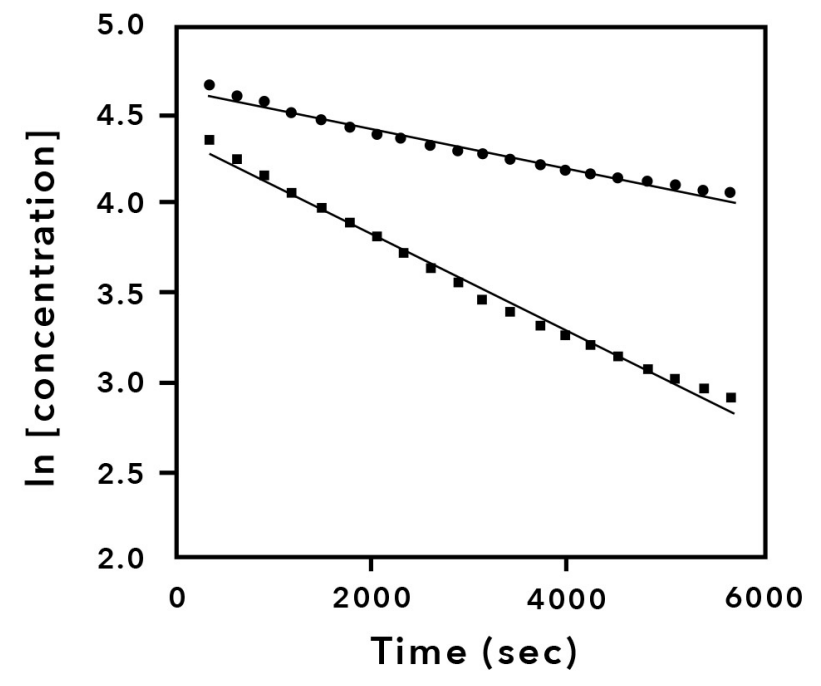

R Square Values in Fitting of the Kinetic Data

\begin{tabular}{|l|c|c|c|c|}
\hline Compound & $\begin{array}{c}\text { Zeroth } \\
\text { order fit }\end{array}$ & $\begin{array}{c}\text { First } \\
\text { order fit }\end{array}$ & $\begin{array}{c}\text { Second } \\
\text { order fit }\end{array}$ & $\begin{array}{c}\text { Half } \\
\text { order fit }\end{array}$ \\
\hline Dione 1 & 0.9457 & 0.9765 & 0.9946 & 0.9626 \\
\hline Trimethylphosphite & 0.9290 & 0.9926 & 0.9893 & 0.9685 \\
\hline Phosphorane 4 & 0.9323 & 0.7734 & 0.5339 & 0.8675 \\
\hline
\end{tabular}

Figure S8. Near-linear pseudo-first order fits are the best fit for the disappearance of $\mathbf{1}(\bullet)$ and $(\mathrm{MeO})_{3} \mathrm{P}(\mathbf{\square})$, whereas phosphorane 4 appearance does not fit first order kinetics, presumably due to its simultaneous decomposition. The table shows R square values resulting from several fittings of the kinetic data. 